Mallawaarachchi, H., Karunasena, G., Sandanayake, Y.G. and Liu, C., 2021. Initiating industrial symbiosis (IS) networks in Sri Lanka: Insights from global projects. In: Sandanayake, Y.G., Gunatilake, S. and Waidyasekara, K.G.A.S. (eds). Proceedings of the $9^{\text {th }}$ World Construction Symposium, 9-10 July 2021, Sri Lanka. [Online]. pp. 369-380. DOI: https://doi.org/10.31705/WCS.2021.32. Available from: https://ciobwcs.com/papers/

\title{
INITIATING INDUSTRIAL SYMBIOSIS (IS) NETWORKS IN SRI LANKA: INSIGHTS FROM GLOBAL PROJECTS
}

\author{
Harshini Mallawaarachchi ${ }^{1}$, Gayani Karunasena ${ }^{2}$, Y.G. Sandanayake ${ }^{3}$ and \\ Chunlu $\mathrm{Liu}^{4}$
}

\begin{abstract}
Industrial symbiosis (IS) is an ideal initiative for co-located industries to gain a competitive advantage through physical exchange of materials, energy, water, and byproducts within a closed loop industrial system. IS has been created a considerable impact on the environmental and economic development through water savings, reduction of raw material extraction and carbon emissions reductions. As many developing countries are suffering from the environmental degradation due to industrial operations, initiating IS networks is vital to improve the business and environmental performance of industries. Since it is a novel concept, it is important to examine the insights from global IS projects to foresee the future challenges. Thus, in this study, PESTEL framework is employed to examine the impact of political, economic, social, technological, environmental and legal external factors on global IS projects. The secondary data collected from nine global IS projects were analysed using PESTEL analysis. The analysis clearly describes the several facets that could influence on industries deploying the IS networks, such as the pressure made by government, external parties, collective cost and environmental benefits, infrastructure sharing, social benefits, and influence made by laws and regulations. Accordingly, a PESTEL framework is developed, which provides a firm base to foresee the possible future changes, challenges and opportunities that can be effectively considered in strategic business decisions for deploying IS networks in Sri Lanka.
\end{abstract}

Keywords: Framework; Global; Industrial Symbiosis (IS); Insights; PESTEL analysis.

\section{INTRODUCTION}

Industrial symbiosis (IS) as an application of industrial ecology (IE), occurs at the interfirm level as it includes exchange of resources among several organisations. According to Chertow (2000), IS engages the traditionally separate industries in a collective approach to gain competitive advantage through physical exchange of materials, energy, water, and by-products offered by geographic proximity. Since its emergence, the research scholars have interpreted this novel concept in various ways by tracking its development (Mallawarachchi et al., 2020). As stated by Chertow and Ehrenfeld (2012), IS engages organisations from different sectors for achieving mutually favourable

\footnotetext{
${ }^{1}$ Department of Building Economics, University of Moratuwa, Sri Lanka, harshinim@uom.lk

${ }^{2}$ School of Architecture \& Built Environment, Deakin University, Australia, gayani.karunasena@ deakin.edu.au

${ }^{3}$ Department of Building Economics, University of Moratuwa, Sri Lanka, ysandanayake@uom.lk

${ }^{4}$ School of Architecture \& Built Environment, Deakin University, Australia, chunlu.liu@ deakin.edu.au
} 
relations by reusing the waste and by-products in an innovative manner. Empirical studies reveal that a number of IS projects has been elevated across the globe amalgamating with the various IS theories and literature, which evidences how vital the application of IS towards achieving its ultimate outcomes. For an example, IS networks in European countries have been impacted considerably on their environmental and economic development through water savings, reduction of raw material extraction and carbon emissions reductions (Tao et al., 2019). Thus, IS has become a major business initiative in many countries all over the world.

Similarly, the concept of IS is an idyllic model to initiate the IS based industrial networks in Sri Lanka as it aims to improve the business and environmental performance of industries mainly through resource efficiency improvements. The industries, a main consumer of primary resources, have become the fastest growing component of the global resource use. However, shaping up the IS business among the local industries is still a challenge specially in developing countries like Sri Lanka. Industrial actors need to have effective and usable methods and tools to predict possible future changes, challenges and opportunities both in their own operations and in their business environments (Korreck, 2018). Based on the existing research, many fruitful insights can be found from global IS initiatives, which may facilitate the initiation of IS networks within the local context.

Thus, this paper focuses on examining the political, economic, social, technological, environmental and legal insights from global IS projects by employing the widely applied PESTEL framework. The localised industries may apply this framework to foresight the challenges and opportunities for IS initiatives within their industry operations as a main implication of this research.

\section{LITERATURE REVIEW ON THE INITIATIVES OF INDUSTRIAL SYMBIOSIS}

The concept of industrial symbiosis (IS) finds its origin in the field of industrial ecology (IE) (Baldassarre et al., 2019). The world's concern on the importance of reducing the resource consumption has been resulted in developing various strategies and pathways. The concept of IS emerged in this regard by supporting the principles of IE, which has been increasingly grown over the few last decades due to its corporative benefits. Chertow and Ehrenfeld (2012) deliberated the improvement of the concept as a systematic approach for implementing the environmentally sound industrial systems. Further to authors, IS engages organisations from different sectors for achieving mutually favourable relations by reusing the waste and by-products in an innovative manner. Geographical proximity of the firms was concerned as a key for emerging IS (Chertow, 2007; Weerasinghe and Sandanayake, 2017).

Thus, a number of IS initiatives have been launched across the globe (European Commission, 2005; Tao et al., 2019), expecting to achieve the sustainable benefits through the exchange of waste, wastewater and other resources. For example, the first model of IS was fully realized in the eco-industrial park (EIP) at Kalundborg, Denmark (Chertow, 2000). Moreover, at least sixty state-level industrial parks have been established in China during last decade, which account for a large proportion of the world's industrial parks (Liu et al., 2018). Choctow Eco-industrial Park, USA, Qijiang Industrial Park, China, Songmudao Chemical Industrial Park, China are the other examples for IS projects initiated by aiming the exchange of wastewater (Carr, 1998; Van 
Beers et al., 2007; Li et al., 2017; Zhang et al., 2017). Boons et al. (2017) further stated that the decision could be influenced by various motives and institutional factors, such as level of trust, policies and regulations and social reasons, and incentives given by the individual industrial entities. Chertow (2007) clearly described that the key to IS for taking the advantage of synergetic possibilities is the geographical proximity of the firms, since it involves physical exchange of resources. However, Mirata and Emtairah (2005) noted that the symbiotic relationships could also happen in long distances and it can include the exchange of knowledge and utilisation of shared infrastructure.

As Chertow (2007) further stated, the efficient resource sharing, emission reduction and waste elimination may also help to reduce the cost and increase revenues as a collective advantage. As stated by Domenech et al. (2019), cost savings, $\mathrm{CO}_{2}$ savings, water savings, reducing the landfilling of waste, eliminating hazardous waste and creating job opportunities are the key sustainable benefits that can be achieved though IS. As Domenech et al. (2019) further explained, IS also facilitates an environment for building new partnerships with other industries, accessing innovation, assisting to achieve environmental policy and company targets and satisfying the corporate social responsibility (CSR) requirements. Indeed, Ghali and Frayret (2019) mentioned that IS is primarily focusing on optimising the use of resources among the different industries for economic, environmental and social gains through a sustainable business. As stated by Morales et al. (2019), IS looks for optimising the material, energy and waste flows through an effective exchange in line with environmental and economic objectives. It is further supported by Maqbool et al. (2019) that optimisation achieved through efficiency gains, energy and carbon savings is a beginning for economically viable IS business coupling with the enhanced environmental performance.

Sri Lanka is facing a severe environmental challenge due to improper disposal of waste, extraction and utilization of non-renewable resources same as the other developing countries across the globe. Specially, the industries a main consumer of the primary resources, have become the fastest growing component of the global resource use. Besides, it has enriched the resource extraction and demand very rapidly. The extract and dump nature of the industrial systems has burdened the reuse of resources, in which the materials and energy are dumped in a linear flow after been used. Thus, the existing environmental degradation due to elevated freshwater utilisation, energy consumption, material extraction and waste disposal, can be overwhelmed through waste and byproducts exchange.

Thus, understanding the current status of global IS business initiatives is vital to foresee the challenges and opportunities that can be affected on the local industry environment when moving towards IS. This study employs the PESTEL framework to determine the political, environmental, social, technological, economic and legal aspects from global IS projects, which may assist predicting the future challenges and opportunities for IS networks in Sri Lanka. The methodology adapted is described below.

\section{RESEARCH METHODOLOGY}

Since this paper aims to examine the insights of global IS projects, qualitative approach was selected. An in-depth investigation was conducted by selecting the existing IS projects in operation. As the most suitable method for selecting the published case studies over the considered period of time, desk review was selected to collect the published data. 
Desk study is a quick and easy method for collecting data from existing sources. It reduces data collection time and adds to the accuracy of conclusion, since the data is collected from reliable published sources. Further, it forbids interviewee biasness and allows researchers to access to valuable information at little or no cost. Thus, the reliable data on IS projects were collected from the published sources. Accordingly, 09 published IS projects were finally chosen considering the research scope and availability of data. Data were collected from the journal articles, which have been published relating to the selected projects during the period of 1989 to 2019 as stated in Table 1.

Table 1: Profile of the selected projects

\begin{tabular}{|c|c|c|}
\hline Project & Global IS projects & Article availability \\
\hline Project A & Kalundborg, Denmark & $\begin{array}{l}\text { Ehrenfeld and Gertler (1997); Chertow } \\
\text { (2007); Domenech and Davies (2011); } \\
\text { Zhang, et al. (2016); Zhang and Chai } \\
\text { (2019) }\end{array}$ \\
\hline Project B & Guitang Group IS Project, China & Zhu et al. (2007) \\
\hline Project C & $\begin{array}{l}\text { Kwinna Industrial Area, } \\
\text { Australia }\end{array}$ & Van Beers et al. (2007) \\
\hline Project D & Tianjin IS Project, China & Shi et al. (2010); Yu et al. (2014) \\
\hline Project E & $\begin{array}{l}\text { Gujiao Eco-industrial Park, } \\
\text { China }\end{array}$ & Song et al. (2018) \\
\hline Project F & Shandong Lubei, China & $\begin{array}{l}\text { Zhang et al. (2015); Zhang et al. (2016); } \\
\text { Zhang and Chai (2019) }\end{array}$ \\
\hline Project G & Choctow Industrial Park, USA & Carr (1998); Domenech and Davies (2011) \\
\hline Project $\mathrm{H}$ & Dunkirk IS Project, France & Morales et al. (2019) \\
\hline Project I & Ulsan Eco-industrial Park, Korea & $\begin{array}{l}\text { Park et al. (2019); Behera et al. (2012); } \\
\text { Kim et al. (2018) }\end{array}$ \\
\hline
\end{tabular}

The data collected from selected projects were analysed using PESTEL framework since it is an ideal technique to identify external factors affecting IS projects and hence, to assess the viability of a new venture. PESTEL framework is briefly described below.

Political aspects: This includes the aspects, such as political and governmental pressure, trade policies, which could impact the industries deploying IS.

Economic aspects: This includes the factors influencing the economic performance of the industries that are deploying the IS business, such as fiscal and taxation policies, interest rates, input cost, waste treatment and discharge cost to name a few.

Social aspects: The influence made by the social environment, the stakeholders of the industries and communities on industries, such as behavioural patterns and cultural effects are considered.

Technological aspects: This includes the developments of technical aspects, such as use of new technologies, innovation, research and development and technical solutions, etc and their impact on the industries that are deploying IS.

Environmental aspects: This includes the ecological and environmental aspects, such as environmental impacts, resource utilisation, waste and energy management and other sustainable policies and their impact on the industries that are engaging in IS. 
Legal aspects: This describes the legal aspects, such as, institutional, local and national level laws and regulations, which could impact the industries deploying IS.

Thus, by using the PESTEL analysis, the political, economic, social, technological, environmental and legal aspects of global IS initiatives were identified by synthesising the existing literature. The key findings derived through data analysis are presented below.

\section{KEY RESEARCH FINDINGS}

The analysis of secondary data collected from the global IS projects revealed several practices in relation to the business and operational environment. The global IS initiatives and practices were reviewed under the six areas of PESTEL analysis.

\subsection{Political Aspects}

The secondary data of IS projects clearly show that there is a pressure of political decision making in initiating IS concept. Specially, the political pressure through environmental protection agencies, non-government organisations, industrial associations and community leaders towards managing the environmental impacts caused due to industrial activities. Further, the lack of support by political parties can be recognised in both Projects E and G. The external pressure made by the political leaders as well as the environmental protection agencies on waste generators in Projects A and D can be highlighted.

There is a firm level concern in developing the new policies for dealing with environmental issues and waste management, which will be used in initiating the new synergetic opportunities reducing the external pressure (Project A)

In Project $\mathrm{C}$, all the industries together with Kwinna Industries Council started exchanging of resources due to increased government pressure to manage the air and water sheds and protect the sensitive marine environment. Furthermore, involvement of at least one government agency for authority is identified in few projects including Project $\mathrm{H}$. In Project $\mathrm{H}$, the local authorities have been involved for managing conflicts between industries, residents and environmental protection organisations. It is evident in Project $\mathrm{G}$ that the park is coordinated by the Industrial Park Authority, while an academic researcher has been appointed as the champion to drive the process through proper coordination of industries in Project I. Further, the involvement of government agencies has become a pressure, where the authority is owned by a government agency or private sector organisation limiting the decision-making ability of other actors of the network. For example, in the symbiotic network of Project F, the owner of the network has limited the decisions taken by other actors of the network.

Accordingly, 06 political insights were derived through review as; the lack of support by political parties (Projects E \& G), the external pressure made by the political leaders and environmental protection agencies on waste generators (Projects A \& D), increased government pressure to protect the environment (Projects F \& H), involvement of at least one government agency for authority (Projects $\mathrm{H}$ ), involvement of local authorities for managing conflicts between industries and community (Projects $\mathrm{G} \& \mathrm{H}$ ) and limiting the decision-making ability of other actors of the network (Projects A, G \& H). 


\subsection{ECONOMIC ASPECTS}

There are number of economic aspects influencing the IS business worldwide. The competition between industries towards engaging with IS collaborations due to collective economic benefits is visible in most of the projects. Thus, several independent by-product exchanges have gradually evolved into a complex web of symbiotic interactions among five co-located companies and the local municipality in Projects A and D.

There has been a by-product exchange primarily begun with steam supply consisting seven main industries in Tianjin Economic-technological Development Area (TEDA) in China, which has been expanded to 81 symbiotic exchanges (Project D)

Similarly, in Project B, industries have been collaborated to improve economic and environmental performance simultaneously. For an example, industries in Project A have reduced the waste disposal cost and transaction cost due to effective information sharing, while Project B has achieved cost reductions through sharing of updated information and easily established cooperative relationships. Indeed, industries have obtained various cost benefits through their collaborative engagement by adhering to the fiscal policies and incentives provided by the government.

The financial assistance given by the Ministry of Knowledge for conducting feasibility assessment of industries (Project I)

Environmental and resource tax have been refined based on resource efficiency and emission reduction by the industries (Project E)

On the other hand, consuming more time to achieve short-term and long-term collective benefits or the longer payback period is another economic factor influencing industries in IS networks. Further, the risk of long-term interdependence of industries also requires attention in IS business. It is evident in Project D that the modifications made by individual actors have led to discontinuous symbiotic exchanges over the time. Further, it has led to shortages of resources and price fluctuations of by-products.

The suspension of production of a food processing plant has led to the breakdown of IS exchanges associated with the firm. Furthermore, the price escalation of by-products, product unavailability within the park in long term (Project D)

In summary, the competition between industries towards engaging with IS industrial collaborations (Projects A \& D), collaborating to improve economic and environmental performance (Projects A, B, E \& I), longer payback period to achieve short-term and long-term collective benefits (Projects A \& D) and influence made by fiscal policies and incentives (Projects A \& D) were recognised as the economic factors influencing IS networks.

\subsection{SOCIAL ASPECTS}

When discussing the social insights that have been influenced on industries in IS networks, the pressure made by social environment can be highlighted in many projects. For an example, the influence made by general public, community leaders and surrounding neighbours of the industrial park can be found in Projects C, E and G. 


\section{All the industries together with Kwinna Industries Council started exchanging of resources due to increased government and community pressure to protect the sensitive marine environment (Project $C$ )}

Nevertheless, lack of trust on other partners and the difficulty in maintaining close relationship with other actors in long term are other influences made by industry stakeholders. Even though, the network began with mutual trust, projects have faced difficulty in maintaining close relationship with other actors in long term.

The industries in the network have faced trust over other partners belonging to the quality of by-products exchanged (Project $F$ )

The suspension of production of a food processing plant has led to the breakdown of IS exchanges associated with the firm (Project D)

The generation of social benefits and contribution to enhance socio-economic development by the industries engaged in IS business is another social insight, which can be recognised in global IS projects. Considering the community needs over flooding and meeting, the quality of life can be identified in Projects $\mathrm{G}$ and $\mathrm{H}$.

The symbiotic network has created job opportunities for public in which about 90-225 employees are currently working in the park (Project $G$ )

Thus, the influence made by general public, community leaders and surrounding neighbours (Projects C, E \& G), lack of trust on other partners (Projects D \& F), difficulty in maintaining close relationship with other actors (Project F), generating social benefits and community needs (Project G) and contribution to enhance socio-economic development (Projects G \& H) were identified as social insights influencing IS networks.

\subsection{TECHNOLOGICAL ASPECTS}

The industries deploying the IS business have obtained various technological improvements and faced several challenges. Symbiotic exchanges have been developed by considering the availability of technology, benefits over investment and to be allowed under the existing laws in Project I. IS is an innovative business opportunity where it promotes sharing infrastructure and public utilities, while creating new business opportunities. The renovation and reuse of industrial complexes adhering to new technologies and innovative infrastructure designing strategies have motivated the industries to engage in IS business. Further, technical expertise and guidance provided by the government agencies are also visible in many IS projects.

\section{Protection Bureau has played a leading role and provide technical expertise} during the development (Project D)

Further, industrial diversity is another innovative insight considered by the industries deploying IS business. As recognised in Projects A and C, diverse regional synergetic opportunities still appear within the network. Further, it has a possibility for expansion of the network.

Project $H$ network is composed by 14 diverse firms, such as power plant, cement factory, steel industry, dust recycling company, agricultural market, etc while 41 diverse regional and industrial institutions are engaged in Project I (Project H, Project I) 
Accordingly, 06 technological insights influencing IS networks were recognised as; promotes sharing infrastructure and public utilities (Projects A, D \& I), creating new business opportunities (Projects D \& I), renovation and reuse of industrial complexes adhering to new technologies (Projects A \& C), using innovative infrastructure designing strategies (Project $\mathrm{C}$ ), technical expertise and guidance provided by the government agencies (Project D) and diverse regional synergetic opportunities (Projects A, C, H \& I).

\subsection{ENVIRONMENTAL ASPECTS}

There are several environmental aspects influencing the industries that are engaging in the IS business. As aimed in IS collaborative business, the reduction of environmental issues has always been considered by many global IS projects.

In Project $\mathrm{C}$, all the industries together with Kwinna Industries Council have started exchanging of resources in order to manage the resources, while protecting the sensitive marine environment. Further, in Projects A, D and E, industries are collectively engaged in generating environmental benefits, such as waste management, water management, energy management, reduction of environmental pollution and providing social benefits, to name a few. The IS network in Project $\mathrm{F}$ has been pre-planned by considering the reduction of the resource utilisation and waste.

The IS in Kalundborg has generated a significant environmental and economic gain through the reduction of waste within the process, which includes ground, surface and wastewater savings as well as the reduction of carbon emissions. The annual savings for the whole network is 15US\$ millions. Further, it has generated over 310US\$ of accumulated savings over the years (Project A)

Further, the environmental liability of each industry in the IS network is visible as all the industries engaged in generating opportunities to reduce environmental impacts through waste sharing.

The partnership of IS in Project G has been promoted both tire recycling and the reuse of treated wastewater to fulfil the non-portable water needs of the co-located industries (Project $G$ )

Hence, collective engagement of industries in generating environmental benefits (Projects A, C, D \& E), pre-planning of networks for reducing resource utilisation and waste discharge (Projects A \& F) and assuring environmental liability of each industry (Project G) were identified as environmental insights, which can influence IS networks.

\subsection{LEGAL ASPECTS}

When discussing about the legal aspects influencing the industries deploying the IS business, the influence by new policies and regulations can be highly recognised. The legislations have a strong impact on waste disposal and recycling. For example, pressure made by new environmental regulations in China, which has been influenced on waste generators in Projects A and D can be highlighted.

The new environmental regulations in China have been influenced on waste generators engaged in IS business (Project D)

Further, the influence made by the industrial development policies on industries in IS business can also be highlighted. For example, new industrial development policies and planning guidelines in China has been influenced on Project A. On the other hand, pricing 
and infrastructure designing strategies have been implemented in Project $\mathrm{E}$ to motivate the industries to engage in symbiotic development.

There was a planning procedure (a corporative plan) for initiating and developing IS network with a careful analysis of the design requirements and planning strategies to meet related necessities (Project A)

The impact made by labour regulations is apparent in Project $H$. The feasibility investigation of the projects has been carried out under the premises of the existing laws in Project I.

In summary, 06 legal insights were derived through analysis as; the pressure made by new environmental regulations (Projects A \& D), industrial development policies and planning guidelines (Projects A \& $\mathrm{H}$ ), impact made by labour regulations (Projects $\mathrm{H} \&$ I), feasibility investigation of the projects under the premises of the existing laws (Projects D \& I) and pricing and infrastructure designing strategies (Projects A \& D). Figure 1 visualises the PESTEL insights for directing the industries towards initiating IS networks. The developed framework can be used in strategic business decision making for deploying the IS networks in Sri Lanka. Following the aim of this study, the key considerations that can be considered in deploying IS networks in Sri Lanka can be identified as follows:

- Setting amendments in national industrial policy and strategy for engaging the new and existing industries towards closed loop IS networks is important to be considered. Under this, sustainable industrial development guidelines can be introduced for initiating waste sharing networks as the industrial by-products by promoting environmentally friendly industrialization. On the other hand, industries may follow these guidelines effectively, if the provisions come into practice as a national policy driven guideline. However, no amendments have been taken place recently in the national policies relating to industries. For an example, many industries are located upstream and near riverbanks polluting the freshwater bodies due to the issues in Industries Citing Policy in Sri Lanka. Thus, it will be a greater challenge to begin IS initiatives along with the current policies and strategies in Sri Lanka.

- Further, since this requires a high initial investment by the industries involved, the willingness of the industries to engage in IS initiatives can be another challenge. Thus, incentivising the industries, introducing tax reductions, and providing lower utility rates for those who are willing to engage in the IS system are aspects to be considered.

- Establishing IS initiatives within the industrial parks in Sri Lanka with existing infrastructure facilities is another critical aspect. The current storage facilities, pipe networks and treatment technologies need major improvements and renovations, which must be facilitated by the government. Thus, designing or renovating new and existing industrial estates with innovating technologies, and facilitating public and infrastructure sharing possibilities will promote industries to be engaged in IS. This may create a network not only for sharing waste but also for exchanging the public infrastructure and technical expertise among the industries as a collective advantage. 

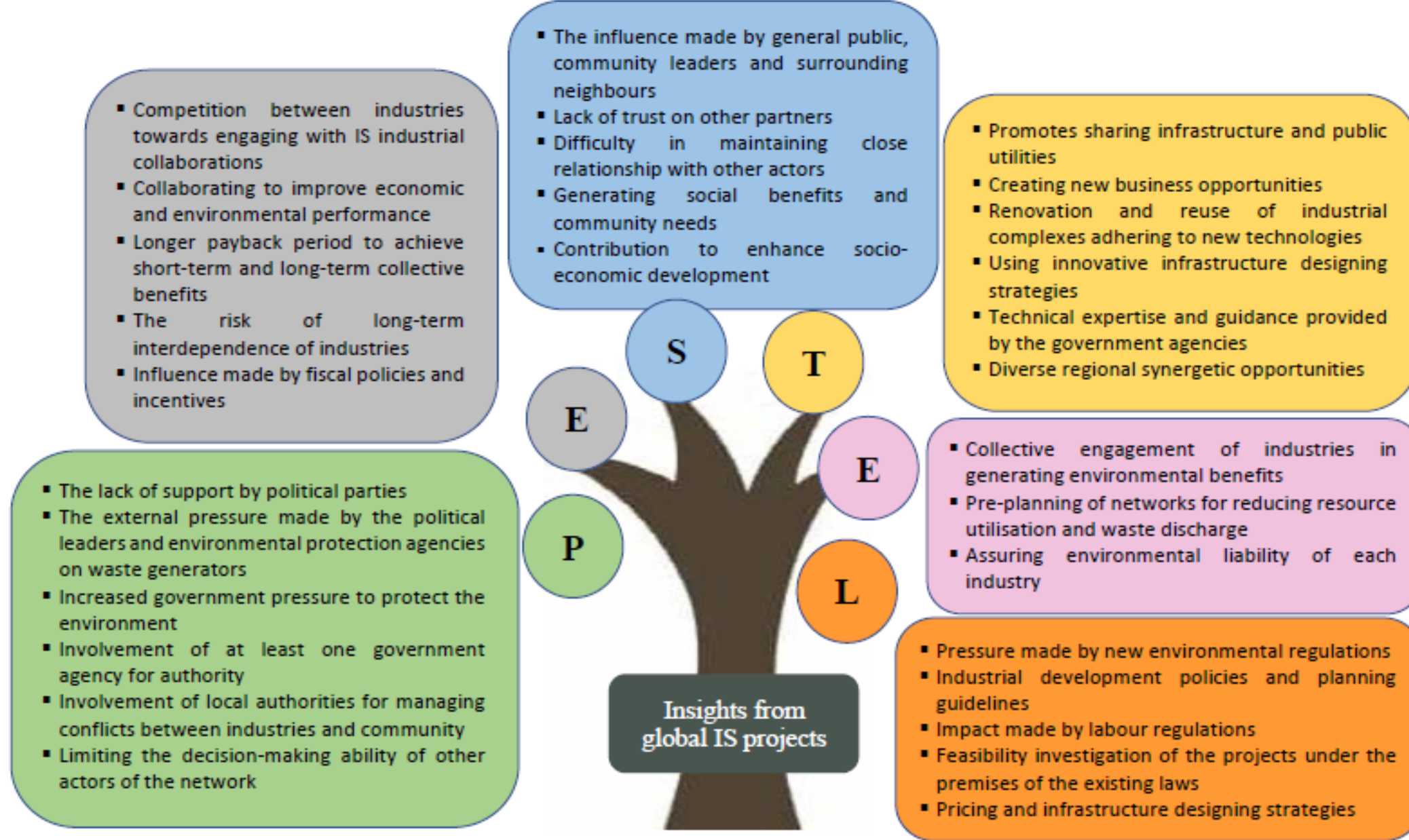

Figure 1: A PESTEL framework for deploying IS networks in Sri Lanka 


\section{CONCLUSIONS AND THE WAY FORWARD}

This paper examines the political, economic, social, technological, environmental and legal insights from global IS projects for initiating IS business initiatives in local context by employing the widely applied PESTEL framework. IS is a collective engagement of co-located industries to gain competitive advantage through physical exchange of materials, energy, water, and by-products, which ultimately improve the business and environmental performance of industries through resource efficiency improvements. The existing environmental degradation due to elevated freshwater utilisation, energy consumption, material extraction and waste disposal of industries can be overwhelmed by directing the local industries towards IS business. The effort of this study was to foresee the challenges and opportunities that can be affected on the local industry environment when moving towards IS. Accordingly, many fruitful insights were derived from global IS projects, such as the pressure made by the government, external parties, collective cost and environmental benefits, infrastructure sharing, social benefits, influence made by laws and regulations, which can be effectively considered in strategic business decisions for deploying the IS business initiatives in Sri Lanka. Since this is an initial impetus to evaluate the challenges for initiating IS initiatives within the local context, the next stage of this research will be to develop an optimised waste (waste materials and wastewater) sharing model for effective resources utilisation of local IS initiatives within a circular nature targeting a high environmental and economic gain.

\section{REFERENCES}

Baldassarre, B., Schepers, M., Bocken, N., Cuppen, E., Korevaar, G. and Calabretta, G., 2019. Industrial symbiosis: Towards a design process for eco-industrial clusters by integrating circular economy and industrial ecology perspectives. Journal of cleaner production, 216, pp. 446-460.

Behera, S.K., Kim, J.H., Lee, S.Y., Suh, S. and Park, H.S., 2012. Evolution of 'designed' industrial symbiosis networks in the Ulsan Eco-industrial Park: 'Research and development into business' as the enabling framework. Journal of Cleaner Production, 29, pp. 103-112.

Boons, F., Chertow, M., Park, J., Spekkink, W. and Shi, H., 2017. Industrial symbiosis dynamics and the problem of equivalence: Proposal for a comparative framework. Journal of Industrial Ecology, 21(4), pp.938-952.

Carr, A.J.P., 1998. Choctaw eco-industrial park: An ecological approach to industrial land-use planning and design. Landscape and Urban Planning, 42(2-4), pp. 239-257.

Chertow, M. and Ehrenfeld, J., 2012. Organising self-organising systems: Toward a theory of industrial symbiosis. Journal of Industrial Ecology, 16(1), pp. 13-27.

Chertow, M.R., 2000. Industrial symbiosis: Literature and taxonomy. Annual Review of Energy and the Environment, 25(1), pp. 313-337.

Chertow, M.R., 2007. "Uncovering” industrial symbiosis. Journal of Industrial Ecology, 11(1), pp.11-30.

Domenech, T. and Davies, M., 2011. Structure and morphology of industrial symbiosis networks: The case of Kalundborg. Procedia-Social and Behavioural Sciences, 10, pp. 79-89.

Domenech, T., Bleischwitz, R., Doranova, A., Panayotopoulos, D. and Roman, L., 2019. Mapping Industrial Symbiosis Development in Europe_typologies of networks, characteristics, performance and contribution to the Circular Economy. Resources, Conservation and Recycling, 141, pp.76-98.

Ehrenfeld, J. and Gertler, N., 1997. Industrial ecology in practice: The evolution of interdependence at Kalundborg. Journal of industrial Ecology, 1(1), pp. 67-79.

European Commission, 2005. Thematic strategy on the sustainable use of natural resources. COM (2005) 670 Final. Brussels: European Commission.

Ghali, M.R. and Frayret, J.M., 2019. Social semantic web framework for industrial synergies initiation. Journal of Industrial Ecology, 23(3), pp. 726-738. 
Kim, H.W., Dong, L., Choi, A.E.S., Fujii, M., Fujita, T., and Park, H.S., 2018. Co-benefit potential of industrial and urban symbiosis using waste heat from industrial park in Ulsan, Korea. Resources, Conservation and Recycling, 135, pp. 225-234.

Korreck, S., 2018. Opening up corporate foresight: What can we learn from open and user innovation?. Journal of Innovation Management, 6(3), pp. 153-177.

Li, B., Xiang, P., Hu, M., Zhang, C. and Dong, L., 2017. The vulnerability of industrial symbiosis: a case study of Qijiang Industrial Park, China. Journal of Cleaner Production, 157, pp. 267-277.

Liu, Z., Adams, M., Cote, R. P., Geng, Y., and Li, Y., 2018. Comparative study on the pathways of industrial parks towards sustainable development between China and Canada. Resources, Conservation and Recycling, 128, pp.417-425.

Mallawaarachchi, H., Sandanayake, Y. G., Karunasena, G., and Liu, C., 2020. Unveiling the conceptual development of industrial symbiosis: Bibliometric analysis. Journal of Cleaner Production, 258 (2020), pp. 120-618.

Maqbool, A., Mendez Alva, F. and Van Eetvelde, G., 2019. An assessment of European information technology tools to support industrial symbiosis. Sustainability, 11(1), pp.131.

Mirata, M. and Emtairah, T., 2005. Industrial symbiosis networks and the contribution to environmental innovation: The case of the Landskrona industrial symbiosis programme. Journal of Cleaner Production, 13(10-11), pp. 993-1002.

Morales, E. M., Diemer, A., Cervantes, G. and Carrillo-González, G., 2019. “By-product synergy” changes in the industrial symbiosis dynamics at the Altamira-Tampico industrial corridor: 20 Years of industrial ecology in Mexico. Resources, Conservation and Recycling, 140, pp. 235-245.

Park, J., Park, J.M. and Park, H.S., 2019. Scaling-up of industrial symbiosis in the Korean National EcoIndustrial Park Program: Examining its evolution over the 10 years between 2005-2014. Journal of Industrial Ecology, 23(1), pp.197-207.

Shi, H., Chertow, M. and Song, Y., 2010. Developing country experience with eco-industrial parks: A case study of the Tianjin Economic-Technological Development Area in China. Journal of Cleaner Production, 18(3), pp. 191-199.

Song, X., Geng, Y., Dong, H. and Chen, W., 2018. Social network analysis on industrial symbiosis: A case of Gujiao eco-industrial park. Journal of Cleaner Production, 193, pp. 414-423.

Tao, Y., Evans, S., Wen, Z. and Ma, M., 2019. The influence of policy on industrial symbiosis from the Firm's perspective: A framework. Journal of Cleaner Production, 213, pp. 1172-1187.

Van Beers, D., Bossilkov, A., Corder, G. and Van, B.R., 2007. Industrial symbiosis in Australian minerals industry: The cases of Kwinana and Gladstone. Journal of Industrial Ecology, 11(1), pp. 55-72.

Weerasinghe, R.P.N.P. and Sandanayake, Y.G., 2017. Collaborative facilities management model: Sri Lankan perspective. Built Environment Project and Asset Management, 7(3), pp. 284-299.

Yu, C., Davis, C. and Dijkema, G.P., 2014. Understanding the evolution of industrial symbiosis research: A bibliometric and network analysis (1997-2012). Journal of Industrial Ecology, 18(2), pp. 280-293.

Zhang, X. and Chai, L., 2019. Structural features and evolutionary mechanisms of industrial symbiosis networks: Comparable analyses of two different cases. Journal of Cleaner Production, 213, pp. 528539.

Zhang, Y., Duan, S., Li, J., Shao, S., Wang, W. and Zhang, S., 2017. Life cycle assessment of industrial symbiosis in Songmudao chemical industrial park, Dalian, China. Journal of Cleaner Production, 158, pp. 192-199.

Zhang, Y., Zheng, H., Chen, B., Su, M. and Liu, G., 2015. A review of industrial symbiosis research: Theory and methodology. Frontiers of Earth Science, 9(1), pp. 91-104.

Zhang, Y., Zheng, H., Shi, H., Yu, X., Liu, G., Su, M. and Chai, Y., 2016. Network analysis of eight industrial symbiosis systems. Frontiers of Earth Science, 10(2), pp. 352-365.

Zhu, Q., Lowe, E.A., Wei, Y.A. and Barnes, D., 2007. Industrial symbiosis in China: A case study of the Guitang Group. Journal of Industrial Ecology, 11(1), pp. 31-42. 